\title{
CORRELATION OF SOCIAL PARAMETERS AND INDIVIDUAL INDICATORS OF INTELLIGENCE
}

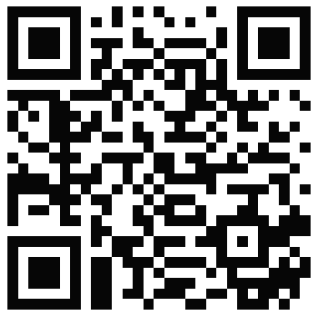

To cite this article:

\author{
Volodymyr Kamyshyn, Dr. Sc. \\ Director, Ukrainian Institute of Scientific \\ and Technical Expertise and Information \\ vkamyshin@gmail.com \\ https://orcid.org/0000-0002-8832-9470
}

\section{Miliena Milenina, PhD}

Head, Giftedness Development Design Department,

Institute of Gifted Child,

National Academy of Educational Sciences of Ukraine

milenina@posteo.de

https://orcid.org/0000-0002-7320-3453
Kamyshyn, V. \& Milenina, M. (2020). Correlation of social parameters and individual indicators of intelligence. Education: Modern Discourses, 3, 122-130.
https://doi.org/10.37472/2617-3107-2020-3-12

\begin{abstract}
It was investigated which of the social parameters are the oldest and most stable structures of our brain, and therefore the most stable regulators of human behavioral strategy. The social parameters that were included in the formation of the neural network of intelligence (in chronological order) were revealed and studied from the most elementary levels of eubacteria to the Australian aborigines at each stage of evolution and ranked in a hierarchy (in chronological order). An empiric research is realized in order to identify the relationships between the intellectual, motivational, characterological and psychophysiological properties of the individual to find ways to optimize the development of academic giftedness. Using the evolutionary tools, the authors identified social parameters that were included in the formation of the neural network of intelligence and presented their paradigm in chronological order. An empiric research has been realized with the aim of identifying the interrelations between intellectual, motivational, characterological, and psycho-physiological properties of an individual to find ways to optimize the development of academic talent. Social parameters significant for the process of formation were included in the package of methods for studying the correlation of behavioral tactics and intellectual indicators. Their results led to the conclusion that the correlation between social parameters and intellectual parameters, which was put forward as a hypothesis, exists.
\end{abstract}

Key words: cultural evolution; giftedness; indicators of intelligence; intellect; mirror neurons; neuron grids; social brain; social evolution, sociopsychological analysis.

\section{INTRODUCTION}

For a long time in science, the idea was that the uniqueness of human being is to use tools and cognitive capabilities. However, as recent studies of behavioral and thoughtful reactions of chimpanzees show, their mental abilities are not inferior to human ones, and in some terms even surpass them. Experiments conducted by the Leipzig Institute of Evolutionary Anthropology, show that the human cognitive apparatus has at least two unique features that 
explain the evolutionary jump and progressiveness of its biological species (Evolyutsiya: Saga o chelovechestve, 2014: p. 54-55). First of all, it is the ability to comprehend the thoughts of another person (which is shown by the children while still in the mother's womb, demonstrating understanding of the words, thoughts and mood of their parents), the ability to intuitively "predict" thoughts and unite mental efforts to identify, understand and achieve a common goal - both to kill a mammoth, or to build a skyscraper. In addition, humanity demonstrates a cultural inertial effect (term of M. Tomasello (Tomasello, 2019, p. 54)) - people modify their tools, improving them, and then transfer these knowledge to the descendants, which led, in the end, to the fact that the invented stone to kill the mammoth after hundreds of years gave way to a sling, later - to a catapult, to a bullet and, eventually, to an intercontinental ballistic missile. This inertia formed the hypothesis of the social brain (Dunbar, 2010).

All brain abilities have arisen and have been refined to solve simple biological tasks reproduction, food and dominance. In this regard, for assessment of the potential of human brain and mental behavior it should be distinguished, on the one hand, its evolutionary and structural constraints, referring to our "monkey" past, and on the other hand - sociobiological selection mechanisms. Referring to the concept of the social brain, we assume that certain social parameters are correlated with individual indicators of intelligence. It is impossible to verify the truth of the assumption without the use of evolutionary tools. In our opinion, the most justifiable is the approach to understanding the intellect as biological, evolutionarily conditioned formation. Accordingly, individual differences in the indicators of intellectual development are due to the effect of physiological factors, and these differences are significantly due to factors of the genotype, affecting stability and variability of indicators of psychometric intelligence (Milankovic, 1998; Bohr, 1958). Proceeding from the evolutionary logic of the formation of intelligence as a network of neurons, we can see how certain parameters of the social brain correlate with certain parameters of individual intelligence.

\section{LITERATURE REVIEW}

It is accepted to allocate several scientific approaches to the study of intelligence and its development:

1. Structural-genetic approach is based on the ideas of J. Piaget, who considered intelligence as the supreme universal way of balancing the subject with the environment. He identified four types of interaction "subject-environment": 1) forms of the lower type, formed by instinct and directly caused by the anatomical and physiological structure of the organism; 2) holistic forms, formed by skills and perceptions; 3 ) integral inevitable forms of operation, formed by figurative (intuitive) pre-operative thinking; 4) mobile, reversible forms, which can be grouped into various complexes, formed by "operational" intelligence (Piaget, 1950).

2. Cognitive approach is based on the understanding of intelligence as a cognitive structure, the specifics of which are determined by the experience of the individual (J. Bruner, O. K. Tikhomirov, etc.). Proponents of this approach carry out an analysis of the main components of the performance of traditional tests to determine the role of these components in determination of test results.

3. Factor-analytical approach in modern psychology has become the most widespread. Its founder is Charles Spearman. He advanced the concept of "general factor" considering intellect as a general "mental energy", whose level determines the success of any tests (Spearman, 1904). The greatest influence this factor makes when performing tests to find abstract relationships. L. Thurstone developed a multifactor intelligence model, according to which there are seven relatively independent primary intellectual abilities (Druzhinin, 2001). According to G. Aysenk, there are strong connections between these factors (Ayzenk, 1995). 
4. Hierarchical models of intelligence also gained popularity. According to this approach, intellectual factors are ranked in the hierarchy by the levels of generalization. Among the most common is the concept of American psychologist Raymond Cattell concerning two types of intelligence that correspond to two of its distinguished factors - "fluid" and "crystalline". According to Cattel, "fluid" intelligence is involved in tasks whose solution requires adaptation to new situations; it depends on the effect of the factor of heredity. And "crystalline" intelligence is involved in solving problems that require an appeal to the past experience (knowledge, skills), largely borrowed from the cultural environment. Intelligence research in the elderly confirms the model of Cattell: with the age (after 40-50 years) the "fluid" intelligence decreases, and the indicators of "crystalline" one remain almost unchanged (Cattell, 1963).

5. No less popular was the model of the American psychologist J. Guilford, who identified three "dimensions of intelligence":

- mental operations;

- features of the material used in the texts;

- intellectual product obtained.

On the basis of this, it was created the so-called Guilford's "cube", which contains 120150 intellectual "factors" (Alder, 2004).

Today, most researchers agree that common intelligence exists as a universal mental ability. In recent years, such new areas of research as the features of "implicit" (or ordinary) theories of intelligence (R. Sternberg), regulatory structures (A. Pages), connection between intelligence and creativity (E. Torrens) and others were being developed.

Proceeding from the fact that our brain consists of "three brains" (Fig. 1) or the main subsystems (each of which received the same name with the period of human evolution, in which it is assumed the system was formed), we need to take into account the significant properties of mental processes that the brain acquired at each stage of evolution.

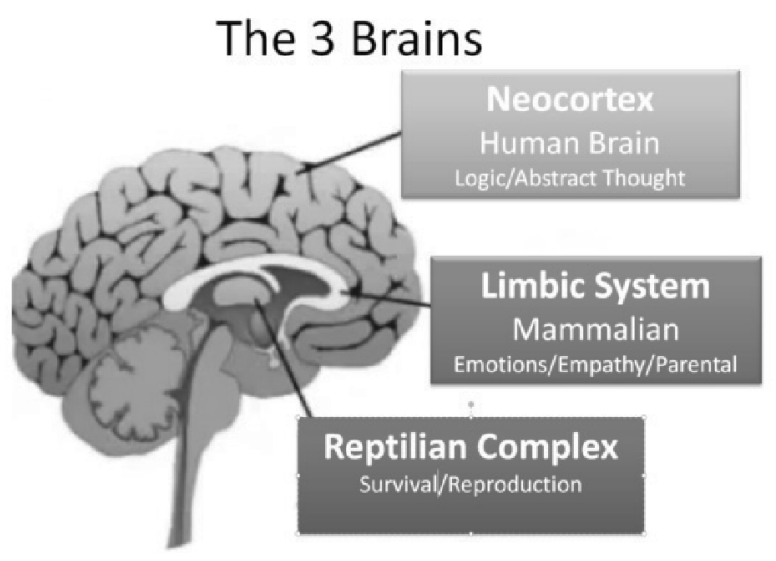

Fig. 1 Components of neurostructure of the brain

1. Neocortex, or human brain (Neocortex, Human Brain) is the newest generation of neurostructures, where high-level mental processes occur, as well as processes for solving complex, integrated problems that control consciousness, sub-consciousness and other higher forms of nervous activity.

2. The limbic system, Mammalian Brain, has a critical significance for emotions and memory. It is more advanced and specialized part of the mammalian brain, except dolphins, higher primates and humans.

3. The cerebellum, or the brain of the reptile (Cerebellum, Stem, Reptilian Brain). The 
most active area of the brain, the environment of subconsciousness, the center of memory and the microprocessor of the brain.

Consequently, considering the intellect as a neural network, it is advisable to consider the neural structures that determine the diversity of intelligence through the prism of evolutionary processes occurring in the brain, at all stages of its formation, based on those studies we have today.

The development model has three phases. First, each new nervous structure is based on previous neural structures. Second, the new brain, as it develops, contains a set of functions as the primitive basis on which it arose and changes the nature of this basis to be more compatible with the new system. Third, the newly integrated system serves as a foundation for a higher level of evolutionary development. Incorporating the previous system into the structure of the new one changes the old function to more adapted one to support the new organism. So, when a neocortex appeared (the brain of a new mammal), the reptile brain and the emotional brain subordinated to this new evolutionary formation, but retained their own spheres of influence and responsibility. Thus, the main side of the nature of any system is preserved when included in a new structure and plays a significant role. The emotional brain (limbic system) at the time of its occurrence changed the nature of the reptile system included in it, but the reptile system continued to work for survival, but more flexible.

In order to understand the biological background of the emergence of intelligence, it is important, in our opinion, to consider how mental processes in the chain of evolution of human ancestors arose and were included in one another - from the brain of the reptile to the stage of neocortex development.

\section{METHODOLOGY}

Summing up dozens of approaches to understanding the biological basis of the functioning of intelligence, we come to the convincing conclusion that it functions on the basis of the properties of the brain as a whole. The brain (primarily the cortex) in the process of intellectual activity acts as a single system with a very flexible and moving internal structure that is adequate to the specifics of the problem and the methods of solution.

The microsystem level is represented by the parameters of the functioning of the neurons (principles of encoding information in neural networks) and the peculiarities of a spread of nerve impulses (speed and accuracy of transmission of information). The macrosystem level reflects the morphofunctional features and significance of individual structures of the brain, their spatial and temporal organization in providing effective mental activity. Consequently, the approach to estimating intelligence is based on the assumption that some of the features of the brain determine the properties of mental processes and form the physiological basis of general (including intellectual) abilities.

So, we have studied the diachrony of the development of social parameters of the brain at all 40 stages of evolutionary development of the human brain - from eubacteria to Tasmanian aborigines. After analyzing the revealed parameters in the path of evolutionary development of the human brain, we can distinguish certain social parameters that were included in the formation of the neural network of intelligence (in chronological order from the most ancient, inherent eubacteria, to the youngest, typical for the Australian Aborigines), namely: mimicry and the ability to swindle with the aim of survival; altruism; ability to general co-operation; speed of decision making in stressing condition; adaptability and attachment; communication skills; ability to defend and avoid conflict; ability to distinguish between truth and falsehood; ability to learn; leadership and hierarchy; invention of games; curiosity; ability to generalize previous experience; selective co-operation; associative consciousness; fast adaptability to 
the negative environment; ability to create new patterns of behavior; hedonism; gambling; consciousness; emotionality, empathy; ability to learn languages; communication; intuition; invention of names; prudence symbolic thinking, abstractness; conscious misinformation; sense of justice; spontaneity; proactivity.

To investigate probable correlations, we developed a package of psychodiagnostic techniques in order to identify the relationships between the intellectual, motivational, characterological and psychophysiological properties of the personality of the senior pupil and the student to find ways to optimize the development of academic giftedness of young people in the educational environment of the school and higher educational institution. The package of psychodiagnostic techniques consists of three blocks aimed at identifying the following indicators:

1. Intelligent indicators [intellectual test by R. Cattel (nonverbal); test "Speech (verbal) abilities" the method "Excluding unnecessary" (for definition of features of conceptual thinking); creativity test by R. Torrance].

2. Personality characteristics [Test of description of behavior by K. Thomas; Bass-Darkie questionnaire (to identify manifestations of motivational aggression); personal questionnaire FLAG test; questionnaire for empathic tendencies by A. Mehrabian, N. Epstein; Orientation profile by $\mathrm{B}$. Bass on revealing personality orientation; method of diagnostics of interpersonal relations by T. Liri; COS test questionnaire].

3. Psychophysiological indices [Test-questionnaire by V. M. Rusalov to study the properties of temperament].

\section{MAIN RESULTS}

A full-scale implementation of the psychodiagnostic methodology (October 2016 - August 2018) was implemented in five higher educational institutions of Ukraine with a coverage of 517 students. The results obtained were pre-processed and the truth of the assumption, which we put forward in the substantiation of the experiment, is established: namely, certain parameters of social behavior correlate with certain parameters of academic intelligence.

Below in the table, there are the values of the correlation coefficients. The farther from zero, the closer the connection of the parameters. Negative values also indicate the presence of correlation, only show that the low value of one parameter is accompanied by a high value of another one (in the case of a normal correlation, the low value is accompanied by low one).

The table contains only those correlations, the significance level of which is $p \leq 0,05$, that is, they are sufficiently significant. When $\boldsymbol{p}$ is close to zero, the correlation is very significant.

Table 1 shows that the level of development of verbal abilities correlates with the following socio-psychological indicators of personality.

Table 1

\section{Correlation of the level of development of verbal abilities with the socio-psychological indicators of personality}

\begin{tabular}{|c|l|c|c|}
\hline \multicolumn{1}{|c|}{ № } & \multicolumn{1}{|c|}{ Indicator } & $\begin{array}{c}\text { correlation } \\
\text { coefficient }\end{array}$ & $\begin{array}{c}\text { level of } \\
\text { significance }\end{array}$ \\
\hline 1 & Verbal aggression & $-0,162$ & 0.046 \\
\hline 2 & Feeling guilty & $-0,199$ & 0.014 \\
\hline 3 & Focus on membership in the group & $-\mathbf{0 , 2 0 9}$ & $\mathbf{0 . 0 1 0}$ \\
\hline 4 & Tendency to adapt & $-0,190$ & 0.018 \\
\hline \hline
\end{tabular}




\begin{tabular}{|c|l|c|c|}
\hline 5 & $\begin{array}{l}\text { Ergency (need to master the subject world, thirst for } \\
\text { activity, desire for mental and physical labor, desire to be } \\
\text { involved in labor activities) }\end{array}$ & $-0,165$ & 0.041 \\
\hline 6 & Authoritarianism & $-\mathbf{0 , 2 3 2}$ & $\mathbf{0 . 0 0 4}$ \\
\hline 7 & Selfishness & $-0,182$ & 0.024 \\
\hline 8 & Dependence on others, conformance & $-\mathbf{0 , 2 5 5}$ & $\mathbf{0 . 0 0 1}$ \\
\hline 9 & Benevolence & $+\mathbf{0 , 3 5 4}$ & $\mathbf{0 . 0 0 0}$ \\
\hline 10 & Desire to dominate & $+\mathbf{0 . 2 0 7}$ & $\mathbf{0 . 0 0 0}$ \\
\hline 11 & Sense of justice & $+\mathbf{0 . 2 8 6}$ & $\mathbf{0 . 0 0 2}$ \\
\hline 12 & Empathy & $-\mathbf{0 , 2 5 5}$ & $\mathbf{0 . 0 0 0}$ \\
\hline 13 & Response to stress: type A behavior pattern & $-\mathbf{0 , 2 1 1}$ & $\mathbf{0 . 0 1 0}$ \\
\hline 14 & Extroversion & & \\
\hline
\end{tabular}

The level of nonverbal intelligence correlates with the following socio-psychological indicators of personality is shown in Table 2.

Table 2

\section{Correlation of the level of nonverbal intelligence with the socio-psychological indicators of personality}

\begin{tabular}{|c|l|c|c|}
\hline № & \multicolumn{1}{|c|}{ Indicator } & $\begin{array}{c}\text { correlation } \\
\text { coefficient }\end{array}$ & $\begin{array}{c}\text { level of } \\
\text { significance }\end{array}$ \\
\hline 1 & Distrust & $-\mathbf{0 , 2 1 0}$ & $\mathbf{0 . 0 0 9}$ \\
\hline 2 & Verbal aggression & $-\mathbf{0 , 2 0 9}$ & $\mathbf{0 . 0 1 0}$ \\
\hline 3 & Hostility to environment & $-0,175$ & 0.030 \\
\hline 4 & Aggressiveness & $-0,167$ & 0.039 \\
\hline 5 & Tendency to compromise & $+\mathbf{0 . 2 0 7}$ & $\mathbf{0 . 0 1 0}$ \\
\hline 6 & Authoritarianism & $-0,159$ & 0.049 \\
\hline 7 & Distrust (according to the Liri test) & $-0,184$ & 0.023 \\
\hline 8 & Dependence on others, conformance & $-0,200$ & 0.013 \\
\hline 9 & Benevolence & $+0,170$ & 0.036 \\
\hline 10 & Desire to dominate & $+\mathbf{0 . 3 0 9}$ & $\mathbf{0 . 0 0 0}$ \\
\hline 11 & Altruism & $\mathbf{- 0 , 2 1 1}$ & $\mathbf{0 . 0 1 1}$ \\
\hline 12 & Intuition & +0.286 & 0.049 \\
\hline 13 & Response to stress: type B behavior pattern & $\mathbf{- 0 , 2 5 5}$ & $\mathbf{0 . 0 0 0}$ \\
\hline 14 & Introversion & $\mathbf{0 . 0 0 0}$ \\
\hline
\end{tabular}

The level of development of conceptual thinking correlates with the following sociopsychological indicators of personality is shown in Table 3 . 


\section{Correlation of the level of development of conceptual thinking with the socio-psychological indicators of personality}

\begin{tabular}{|c|l|c|c|}
\hline \multicolumn{1}{|c|}{ № Indicator } & $\begin{array}{c}\text { correlation } \\
\text { coefficient }\end{array}$ & $\begin{array}{c}\text { level of } \\
\text { significance }\end{array}$ \\
\hline 1 & Tendency to adapt & $-0,172$ & 0.034 \\
\hline 2 & Tendency to compromise & $+\mathbf{0 . 1 8 7}$ & $\mathbf{0 . 0 2 1}$ \\
\hline 3 & Tendency to give socially desirable answers & $-\mathbf{0 , 2 6 7}$ & $\mathbf{0 . 0 0 1}$ \\
\hline 4 & Dependence on others, conformance & $-0,166$ & 0.040 \\
\hline 5 & Benevolence & $-0,178$ & 0.028 \\
\hline 6 & Introversion & $-\mathbf{0 , 2 1 1}$ & $\mathbf{0 . 0 0 0}$ \\
\hline
\end{tabular}

Thus, according to our research, it was discovered that the higher intelligence (the general factor g according to Spearman) is, the less person is aggressive, conformal, friendly and authoritarian. At the same time, he/she has a desire for dominance, although it does not manifest itself in behavior. In addition, he/she has the ability to cooperate, curiosity, orientation towards membership in the group.

\section{CONCLUSIONS}

Regarding the correlation of the level of intellectual abilities with the types of temperament, it was found that those with a high level of intellectual abilities can possess any combination of properties of temperament. The same tendency is observed in the respondents who have the same temperament: the indicators on tests for determining the intellectual abilities are different. Speaking of the connection between temperament and mental abilities, Y. Streljau emphasizes that the role of the properties of temperament is reduced primarily to the influence on the dynamics of the flow of intellectual processes. This dynamics can be manifested in such characteristics of mental work as speed of actualization of information, speed of intellectual processes, stability and switching attention, durability of memory, mental performance, etc. In general, we can say that the properties of temperament are manifested in individual differences in the execution of assimilated operations. The analysis showed the independence of intellectual and temperamental characteristics of the individual.

By attempting to establish the interdependence of personality traits and the level of development of intelligence through the detection of correlations between the basic properties of the individual and the main intellectual factors, scientists have resorted to repeatedly. There are a number of works that compare the results obtained when testing the subjects with tests G. Aysenk and Wechsler Adult Intelligence Scale. The results of such studies complement each other and do not contradict our data. The features of temperament do not affect the content, motives or goals of human activity, but determine the dynamic side of behavior (tempo and rhythm of activity, energy, etc.).

Factor analysis of the results obtained in the studies shows the independence of the intellectual and temperamental characteristics of the individual. However, one should emphasize the correlation between individual manifestations of temperament and intelligence. It is found that the lower the level of intelligence is, the more positive connections between the features of temperament and intelligence are, first of all - verbal. The properties of 
temperament associated with activity, emotionality and sociability are manifested in early childhood, are relatively stable and, most likely, largely depend on the effects of the genotype.

It is also established that with the individual indicators of intelligence the emotional state of the respondent is correlated. Thus, more optimistic and cheerful students were more successful in verbal tasks, and students with a predominantly pessimistic state demonstrated greater success in solving non-verbal problems.

It should be noted that all correlations relating to one indicator of individual intelligence and a set of social parameters are only characteristics of the contribution of the genotype to population variability. This means that the study of the process of interaction between the genotype and the environment, social parameters and individual intellectual parameters in the process of developing a specific phenotype in a particular individual is a separate independent task. The analysis of social interaction tactics only indicates what directions of development can be promising. For example, it has been found that musical abilities are correlated with mathematical, abstract thinking and verbal intelligence and are characterized by a negative correlation with empathy, and therefore it is appropriate to pay attention to the development of all interconnected parameters. As is known, properties of temperament associated with activity, emotionality and sociability, ability to freeze in a stressful situation, or, conversely, to resort to active action, are manifested in early childhood, are relatively stable and, to a large extent, depend on the effects of the genotype. Therefore, the presence of correlations of these indicators with certain parameters of intelligence can be advantageous in determining perspective development strategies, because we can identify the social parameter at a much earlier stage than to diagnose intellectual talent.

Thus, numerous studies show that human intellect is a complex system of different abilities. In its formation, undoubtedly, hereditary mechanisms are involved, but it should not be assumed that heredity is a decisive factor in determining the level of intelligence of a particular person. Favorable environmental conditions, from the early stages of development, are, of course, able to positively affect intelligence. Psychologists-practitioners and teachers, whose main task is to create an adequate environment for maximizing the realization of all human capabilities, should realize this to the fullest. Even with an unfavorable genotype, a wellchosen development environment can contribute to the maximum revelation of potential. As we see, the revelation of the basic laws of psychological development is impossible without the use of evolutionary tools. To understand the individual characteristics of the human psyche we should first to refer to the general nature of human being as a biological species and to the mechanisms of evolutionary formation of species characteristics. The nature of human being consists of the levers and the mechanisms of their adjustment, and they are invisible to their carrier.

Ability to find in each child own inherent points of perception and giftedness, forms the essence of pedagogical and parenting tact, and finding the "keys" to potential abilities, their maximum development requires exceptional attention, insight, and work.

\section{REFERENCES}

Alder, G. (2004). CQ: Boost your creative intelligence: powerful ways to improve your creativity quotient. Kogan Page Business Books

Ayzenk, G. Yu. (1995). Intellekt: novyiy vzglyad [Intelligence: a new view]. Voprosyi psihologii, Rossiyskaya akademiya obrazovaniya, 1, 111-131. (in Russian)

Bohr, N. (1958). On atoms and human knowledge. Daedalus 87(2), 164-175

Butovskaya, M. L. \& Faynberg, L. A. (1993). U istokov chelovecheskogo obschestva: monohrafiia [At the origins of human society: monograph]. Moskva: RAN, Institut etnologii i antropologii im. Mikluho-Maklaya. (in Russian) 
Cattell, R. B. (1963). Theory of fluid and crystallized intelligence: A critical experiment. Journal of Educational Psychology, 54, 1-22

Dreval, A. V. (2005). Intellekt XXX: Intellektualnoe chtenie $v$ zhanre: monohrafiia [Intellect XXX: intelligent reading in the genre: monograph]. Moskva: Toruse Press. (in Russian)

Druzhinin, V. N. (2001). Kognitivnyie sposobnosti: struktura, diagnostika, razvitie: monohrafiia [Cognitive abilities: structure, diagnosis, development: monograph]. Sankt-Peterburg; Imaton. (in Russian)

Dunbar, R. I. (2010). How Many Friends Does One Person Need?: Dunbar's Number and Other Evolutionary Quirks. London: Faber and Faber

Dyachenko, O. M. (1997). Problema individualnyih razlichiy $v$ intellektualnom razvitii: monohrafiia [The problem of individual differences in intellectual development: monograph]. In Voprosyi psihologii, 4, (pp. 138-142). Moskva: Rossiyskaya akademiya obrazovaniya

Evolyutsiya: Saga o chelovechestve [Evolution: The Saga of Humanity]. (2014). V mire nauki, 11. (in Russian)

Golubeva, E. A. (1993). Sposobnosti $i$ individualnost: monohrafiia [Abilities and personality: monograph]. Moskva, Prometey. (in Russian)

Goulman, D. (2008). Emotsionalnyiy intellekt: monohrafiia [Emotional Intelligence: monograph]. Moskva: AST Moskva, Hranitel. (in Russian)

Gribanov, A. V., Deputat, I. S., Kanzhin, A. V. (2006). Psihofiziologicheskiy analiz strukturyi intellekta detey mladshego shkolnogo vozrasta pri sindrome defitsita vnimaniya $s$ giperaktivnostyu [Psychophysiological analysis of the structure of the intellect of primary school children with attention deficit hyperactivity disorder]. Ekologiya cheloveka, 12, 38-41. (in Russian)

Lipton, B. (2010). Biologiya ubezhdeniy: Kto upravlyaet soznaniem kletok: monohrafiia [Biologiya ubezhdeniy: Kto upravlyaet soznaniem kletok: monograph]. Moskva: Sofiya

Luchinin, A. S. (2004). Psihofiziologiya: monohrafiia [Psychophysiology: monograph]. Rostovna-Donu: Feniks

Milankovic, M. (1998). Canon of insolation and the Ice-age problem. Belgrad, Royal Serbian Sciences

Piaget, J. (1950). The Psychology of Intelligence. London: Routledge and Kegan Paul

Spearman, C. (1904). General intelligence, objectively determined and measured. American Journal of Psychology, 15, 201-293.

Tomasello, M. (2019). Becoming Human: A Theory of Ontogeny. Harvard University Press

Weiss, M. L. \& Mann, A. E. (1985). Human biology and behavior: an anthropological perspective. $4^{\text {th }}$ edn. Boston: Little, Brown, and Company

Zhukov, D. A. (2014). Stoy, kto vedet? Biologiya povedeniya cheloveka i drugih zverey: monohrafiia [Wait, who is leading? Biology of human and other animal behavior: monograph]. Moskva: Alpina non-fikshn 